\title{
Potencial social y político de la planeación local y el presupuesto participativo en Medellín (Colombia) para fortalecer la democracia latinoamericana
}

\author{
Alberto León Gutiérrez. Universidad de Antioquia, Medellín, Colombia. \\ Luis Alberto Hincapié. Universidad de Antioquia, Medellín, Colombia. \\ Gloria María Villa. Universidad de Antioquia, Medellín, Colombia.
}

Resumen | El Programa de Planeación Local y Presupuesto Participativo (PplpP) de Medellín se revela y exalta como experiencia novedosa tanto para Colombia como para Latinoamérica, en tanto articula la planeación del desarrollo al presupuesto participativo (PP) por senderos normativos, político-institucionales y sociales. Esta particularidad lo distingue de otros pp latinoamericanos, que tienden a interpretarse habitualmente desde dos aproximaciones antagónicas: como estrategia de globalización contrahegemónica (Santos, 2007) o como estrategia liberal de gobernabilidad (Goldfrank, 2006; Montecinos, 2009). Para evidenciarlo, se reseña la discusión entre ambas perspectivas de los PP en América Latina y se presentan las características que hacen novedosa la experiencia del PPLPP. Se devela su potencial social y político para fortalecer apuestas democráticas al activar la participación ciudadana en instancias de decisión sobre la inversión de parte del presupuesto municipal, unida a la dinamización del ejercicio de la planeación participativa para orientar el desarrollo local (Gutiérrez \& Sánchez, 2012).

PALABRAS CLAVE | globalización, participación ciudadana, planificación del desarrollo.

ABstract | The Medellin Local Planning and Participatory Budgeting Program (PPLPP) is presented and commended on as an innovative experience for both Colombia and the rest of Latin America, considering its integration of development planning and participatory budget $(P P)$ through the use of regulatory, political, institutional and social means. This peculiarity distinguishes Medellin PP from other Latin American programs in similar lines, which usually tend to be interpreted from two opposing approaches: as a strategy of counter-hegemonic globalization (Santos, 2007) or as a liberal governance strategy (Goldfrank, 2006; Montecinos, 2009). To demonstrate the above, the discussion between the two perspectives of PP in Latin America is reviewed and the characteristics that make the PPLPP experience novel are shown. Lkewise, the article exhibits their social and political potential to strengthen democratic stakes by enabling citizen participation in decisionmaking on the city budget investment, combined with the dynamism of the exercise of participatory planning to guide local development.

KEY WORDS $\mid$ globalization, citizen participation, development planning. 


\section{Introducción}

Los Presupuestos Participativos (PP) surgieron en América Latina enmarcados por transformaciones económicas, sociales y políticas producto de los procesos de globalización que tienden de alguna manera, entre otras cosas, a profundizar la democracia como proyecto político y la participación como su forma práctica por excelencia. A la par, contradictoriamente, estos cambios también han generado condiciones propias para vigorizar el modelo económico neoliberal, que atenta - precisa y especialmente- contra los derechos ciudadanos, tanto individuales como colectivos. El impulso democrático, por un lado, y neoliberal por el otro, demarca tensiones que repercuten en la interpretación, análisis y valoración de experiencias de participación como los pe, fruto de la forma como en cada caso se administran y dirimen las situaciones conflictivas entre neoliberalismo y democracia. Se deduce así, de acuerdo con Goldfrank (2006), que el pp no es un instrumento neutral. La experiencia de Medellín (Colombia) se torna novedosa al vincular, directa y explícitamente, el pp con los procesos de planeación del desarrollo por la vía jurídica, político-institucional y social, en los ámbitos territoriales de corregimiento, comuna, municipio, departamento y la Nación. De esta forma, activa un potencial social y político, que fortalece la apuesta por la democracia en medio de sus tensiones con el neoliberalismo, enmarcadas por la instauración de tendencias globales comunes.

En el seno de las transformaciones sociales, económicas y políticas latentes se evidencia la transición latinoamericana, en los últimos veinte años, hacia regímenes políticos democráticos, acompañados de expresiones de movilización de una sociedad civil que, a diario y cada vez con mayor fuerza, reclama profundizar los escenarios, las formas y los mecanismos de participación en la toma de decisiones. Estas tendencias globales, al observarse en los municipios, han servido de nicho a las condiciones necesarias para que emerjan los Pp: una movilización social que exige la implementación del pp y un escenario político-institucional que lo posibilita (Navarro, 2005; Goldfrank, 2006; Aguirre, 2010; Gómez, 2007; Gutiérrez \& Sánchez, 2012; Velásquez \& González, 2010), el cual, la mayoría de las veces, se ha simplificado como voluntad política del gobernante. Ambas condiciones son complementarias y contradictorias, en tanto desde el régimen político tradicional se pretende imponer el modelo económico neoliberal y, al mismo tiempo, los efectos de este sistema económico, negativos para las mayorías, suscitan la movilización ciudadana y el reclamo de participación directa en espacios de toma de decisiones de corte político y público. Así, la tensión entre neoliberalismo y democracia se concreta, de manera explícita, en la experiencia de los pP y tiende a resolverse en favor del uno o de la otra, en razón a cómo estén configuradas las dos condiciones comunes a los casos de pp en los países de América Latina. Colombia, obviamente, no es la excepción.

En esta tensión, priman cuatro perspectivas para interpretar los múltiples casos documentados. Esto es, los pP son considerados: i) experiencia de globalización contrahegemónica (Santos, 2007); ii) herramienta para generar gobernabilidad en coexistencia con los postulados neoliberales; iii) recurso que favorece el desarrollo capitalista en tanto estabiliza la democracia, y iv) riesgo para la democracia 
representativa, que atenta contra la legitimidad de los gobernantes elegidos (Goldfrank, 2006). Este es el marco de referencia para analizar el sentido social y político de una experiencia como la de Medellín en materia de planeación local y presupuesto participativo. Más que identificar la perspectiva que mejor corresponde con este caso en particular, la pregunta es cuáles son las enseñanzas y posibilidades reales que ofrecen los PP para el cambio o perpetuación de un régimen político democrático sustentado en los derechos civiles, sociales, políticos, económicos, culturales y ambientales, en coexistencia con un modelo económico que atenta sistemáticamente contra los mismos derechos. Esto es, indagar por las alternativas que brinda la experiencia en Medellín a la contradicción entre régimen político y modelo económico para, desde ella, ofrecer alternativas interpretativas a los latinoamericanos, que posibiliten dibujar perspectivas para su fortalecimiento.

La respuesta tiende a ser positiva: en la tensión que se genera del encuentro entre democracia y neoliberalismo, la articulación de la planeación del desarrollo con la destinación participativa del presupuesto que significa el pP, revela condiciones para el fortalecimiento democrático y para contrarrestar los efectos sociales y políticos del modelo neoliberal. Es este el caso del Programa de Planeación Local y Presupuesto Participativo (PPLPP), que denota como característica distintiva de otras experiencias en América Latina, la vinculación del pP con los procesos de planeación del desarrollo municipal, de comuna y de corregimiento. Esta característica, más allá de la dicotomía entre las perspectivas liberal, conservadora, de izquierda ortodoxa o contrahegemónica, representa un potencial social y político para la construcción y fortalecimiento de la democracia (Gutiérrez \& Sánchez, 2012).

La articulación entre los presupuestos participativos y los procesos de planeación del desarrollo, como se señaló anteriormente, acontece por vía jurídica, político-institucional y social. En materia normativa, el PPLPP se enmarca a nivel nacional en la Ley 134 de 1994, la cual desarrolla los mecanismos de participación ciudadana; y en la Ley 152 de 1994, mediante la cual se instauró en Colombia el Sistema Nacional y Territorial de Planeación del Desarrollo. En el nivel municipal, el pplpp remite a los acuerdos 043 de 1996, que crea el Sistema Municipal de Planeación, y 043 de 2007, que lo reformula y amplía. En concreto, son el Acuerdo 043 de 2007 y su Decreto reglamentario 1073 de 2009, los encargados de regular y poner en vigencia el PPLPP, conectando normativamente la estrategia de PP con los procesos de Planeación del Desarrollo Local (PDL) en las dieciséis comunas y los cinco corregimientos en que se encuentra dividida administrativa y territorialmente la jurisdicción del Municipio de Medellín. Ambas normas están soportadas en la legislación nacional puesta en vigencia a partir de 1994, especialmente la alusiva a planeación del desarrollo, ordenamiento territorial, participación ciudadana, presupuesto y régimen municipal, que despliegan y concretan el espíritu de la reforma constitucional colombiana de 1991. Esta articulación normativa es soporte para la vinculación político-institucional del ppLpp; en efecto, el Acuerdo 043 de 2007 incluye y articula, sinérgica y dialécticamente, la planeación local y el presupuesto participativo como componentes del Sistema Municipal de Planeación (SMP), definiendo las relaciones del pPLPp con el sistema mismo y con los demás subsistemas, componentes y actores que le son propios. A su vez, el SMP está inmerso en el 
Sistema Nacional de Planeación (SNP), en el que deben guardarse relaciones vinculantes entre los Planes Nacional, Departamentales y Municipales de Desarrollo y, cuando se presente, con los planes estratégicos Metropolitanos; asimismo, deben inscribirse en los principios de concurrencia, subsidiariedad y complementariedad que consagra la norma para garantizar la financiación y correspondiente realización de los programas y proyectos contenidos en cada plan de desarrollo. La activación de procesos de planeación a nivel corregimental, comunal, municipal, metropolitano, departamental y nacional ocurre, entre otras cosas, por la movilización que los actores sociales, académicos, gubernamentales y privados, realizan de los recursos institucionales de que disponen en cada ámbito territorial de aplicación. Se plasma así la articulación social que logra el PPLPp, en tanto dinamiza la participación en el ejercicio de la planeación del desarrollo no solo en la respectiva comuna y corregimiento, al interior del municipio, sino con ámbitos de mayor alcance: el mismo municipio, el departamento y la Nación.

Los nexos normativos, político-institucionales y sociales que soportan el PPLPP denotan la corresponsabilidad de los tres componentes con un régimen político democrático como el definido por la Constitución Política colombiana de 1991, en el marco de un Estado social de derecho. En correspondencia, la experiencia genera condiciones para contrarrestar tendencias negativas del modelo económico neoliberal que atentan contra la democracia; es este, en esencia, un auténtico potencial social y político del PPLPP. Para presentarlo se enmarcan, a continuación, las perspectivas para asumir los pp latinoamericanos en las condiciones particulares que marcaron su ingreso a la globalización, en especial, la transición democrática; se definen las posibles interpretaciones; posteriormente, se presenta con mayor detalle la articulación entre planeación local y presupuesto participativo en Medellín; y, finalmente, se concluye con el potencial social y político propio de la experiencia, orientado a fortalecer la democracia y contrarrestar el impacto negativo del neoliberalismo en medio de las tensiones entre régimen político y modelo económico.

\section{Contrahegemonía y gobernabilidad liberal}

Cuatro perspectivas se señalan en América Latina para interpretar los Pp. Una, contrahegemónica (Santos, 2007), en la que se plantean alternativas al modelo neoliberal y las tendencias que impone; se trata de una perspectiva cercana a la interpretación de la izquierda renovada y posautoritaria, que veía en el pp una estrategia para relegitimar el Estado de cara a los ataques neoliberales, haciéndolo efectivo, transparente y redistributivo, controlado por la ciudadanía a través del pP (Goldfrank, 2006). La segunda perspectiva es liberal; comparte con la nueva izquierda las aspiraciones de reducir la pobreza y ponerle fin a la corrupción y el clientelismo, pero ve el PP como herramienta para generar gobernabilidad en coexistencia con los postulados neoliberales (Goldfrank, 2006; Montecinos, 2009). La tercera perspectiva proviene de la izquierda ortodoxa, que concibe el pp como recurso a favor del desarrollo capitalista y estabilizador de la democracia, al estimular la confianza ciudadana en el gobierno, ayudando a la burguesía a manejar las crisis del capitalismo y socavando la revolución (Goldfrank, 2006). Finalmente está la perspectiva conservadora, que 
asume el PP como un riesgo para la democracia representativa, que atenta contra la legitimidad de los gobernantes elegidos (Goldfrank, 2006).

Para el análisis del pP en Latinoamérica, interesan las perspectivas contrahegemónica y liberal, en tanto ofrecen posibilidades de perfeccionamiento de este tipo de experiencias, en lugar de descartarlas como hacen las perspectivas conservadora y de izquierda ortodoxa. Entre contrahegemonía y gobernabilidad liberal, los pP permiten observar la tensión entre el neoliberalismo como modelo económico y la democracia como régimen político. En efecto, los cambios económicos, sociales y políticos que implicó la globalización configuraron el escenario ante el cual los PP se presentan como estrategia contrahegemónica (Santos, 2007) y a la vez para que se les utilice como estrategia liberal de gobernabilidad (Goldfrank, 2006; Montecinos, 2009).

Como proceso histórico que penetra y reformula todos los ámbitos de la vida societal y que tiene implicaciones de gran relevancia en la época contemporánea (Gutiérrez \& Sánchez, 2009), la globalización conllevó mudanzas económicas, sociales y políticas que guardan relación con las interpretaciones posibles sobre las experiencias de PP (figura 1). En materia económica, definió un modelo neoliberal, que implica cambios como la internacionalización de capitales, liberalización del mercado, bloques económicos y movilidad de mano de obra; genera ampliación del mercado; e implica privatización de las empresas públicas y liberalización en las tasas de interés (Boisier, 2005; Cárdenas \& Díaz, 2011). En materia social, implicó interacción funcional de actividades culturales (García, 1995); la expansión y uniformidad de las aspiraciones humanas, en que se sustituye el apego a las tradiciones por un destino común promisorio (Squella, 1997), mientras el mayor impacto sociocultural se refleja en una cultura de mercado y consumo alimentada por el flujo de las comunicaciones (Lechner, 2004), unida a lo propio, la historia y cultura locales (Ospina, 2001). En lo político, la globalización se percibe acogida por la democracia (Gutiérrez \& Sánchez, 2009), con privilegios por la descentralización y reducción del Estado (Rodríguez, 1998). Estos cambios generaron escenarios de tendencias contradictorias:

... la fragmentación social por la vía del individualismo que promueve el modelo económico global, a la par que se revitaliza la participación producto de las desigualdades que genera este modelo; la búsqueda de relaciones equitativas en el marco del neoliberalismo; la mayor disponibilidad de tecnología y recursos de la comunicación, que sin embargo, no están al acceso de la mayoría; la búsqueda por la sostenibilidad en el marco de lógicas de explotación capitalista; la concentración de la población en grandes ciudades por migración y desplazamiento forzado, generadores de precariedad y condiciones de vida poco dignas; el propósito de consolidar la democracia como sistema político, bajo las presiones del modelo económico que la tensiona y condiciona. (Vélez et al., 2010, p. 36) 
FIGURA I | Tendencias sociales, políticas y económicas de la globalización

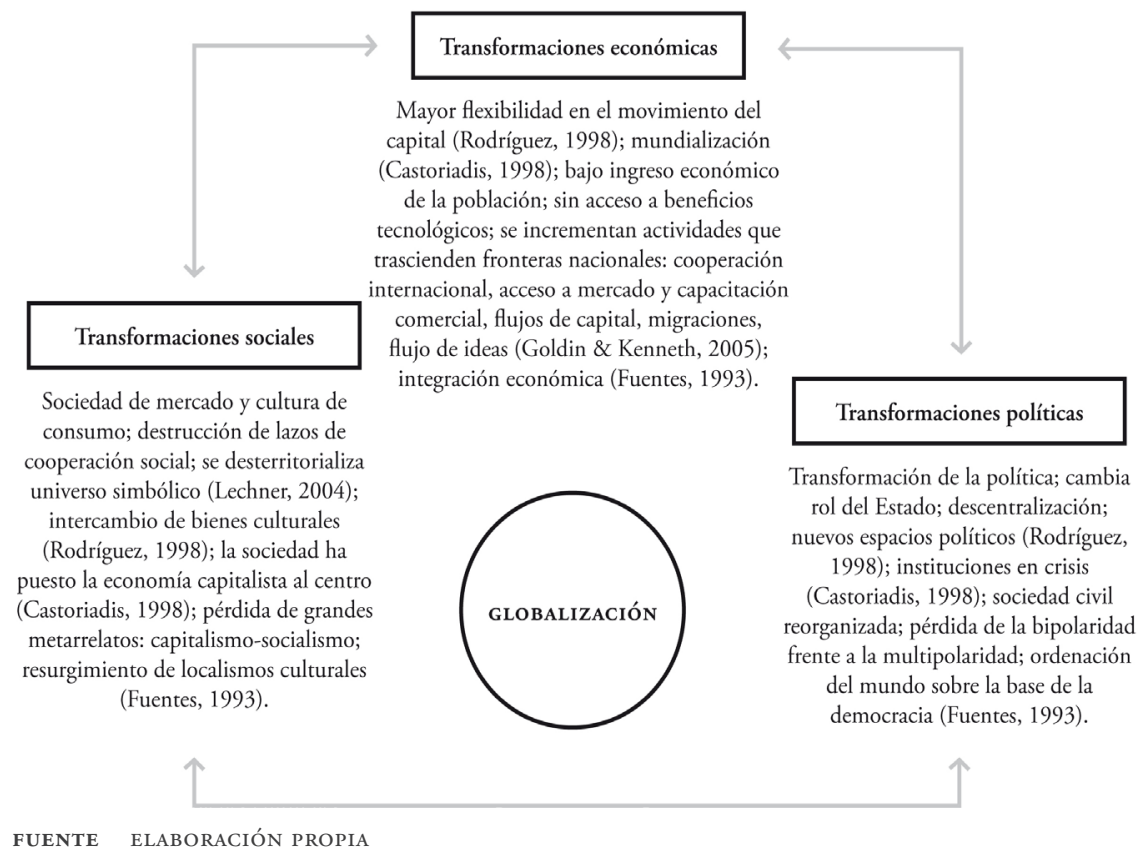

Signadas por la contradicción, emergen las perspectivas contrahegemónica y la liberal; desde ellas, el PP admite ser interpretado como respuesta al neoliberalismo, con posibilidades de incidir en las tendencias globales que llevaron a la situación actual: puede ser asumido como una experiencia de globalización contrahegemónica, en tanto ejemplo de las "luchas nacionales locales cuyo éxito impulsa su reproducción en otras localidades o redes que están experimentando luchas similares" (Santos, 2007, pp. 31-32). Sin embargo, esta es solo una de las posibles interpretaciones y, en particular, atinente al caso de Porto Alegre (Brasil). Ello porque ya no se trata de un proyecto exclusivo de izquierda (Goldfrank, 2006). Al contrario, una idea más "liberal del Presupuesto Participativo, asociada a un nivel más consultivo de participación, estaría tomando mayor fuerza o ascendencia en el resto de la región" (Montecinos, 2011, p. 64), después de que las tendencias hacia la descentralización y democratización estimularon su puesta en práctica, "especialmente donde los partidos de izquierda estaban aliados con movimientos sociales que demandaban tanto democracia como mejoras en los servicios urbanos" (Goldfrank, 2006, p. 5). La tendencia hacia una u otra perspectiva estaría determinada por la intención de los diseñadores, la descentralización y el rol tanto de los partidos políticos como de la sociedad civil en los lugares donde se desarrollen experiencias de pp (Montecinos, 2011). Son, pues, los actores en cada experiencia los que inclinan la balanza a favor de una perspectiva u otra, resolviéndose en cada caso de pp la tensión entre neoliberalismo y democracia. No obstante, la respuesta particular que desde cada experiencia de PP puede brindarse está unida a las condiciones requeridas para la 
emergencia de su surgimiento en América Latina, las cuales también provienen de los cambios generados con la globalización.

Las tendencias expuestas se instauraron en Latinoamérica de forma particular, constituyendo un nicho para las condiciones que originaron los pp. En efecto, por un lado, se generó el marco institucional democrático; y por otro, la movilización social necesaria, fruto de la tensión entre el sistema político democrático y el modelo económico neoliberal. Para ello fue necesario que la movilización social lograra incursionar en el escenario político-institucional en los municipios brasileños mediante la organización política en un partido de izquierda y su victoria electoral. Sin embargo, esta no fue la única condición requerida, en tanto la transición de regímenes dictatoriales hacia los democráticos fue también indispensable para que este tipo de elecciones pudiera realizarse.

Desde la transición dictatorial hacia la democracia, coexisten las dos condiciones para el surgimiento de los PP y, en ellas, se manifiesta la tensión entre neoliberalismo y democracia, que da lugar a sus variadas interpretaciones. Desde el origen mismo de la globalización, convergen tanto la fuerza social que se moviliza en Latinoamérica reclamando escenarios democráticos, como los promotores de la reestructuración económica mundial en torno al neoliberalismo, que, a su vez, promovían el ideal democrático. La "redemocratización latinoamericana se enmarca en la ofensiva desatada por Estados Unidos para, a la vez que enfrenta la crisis internacional, reestructurar en provecho propio la economía capitalista mundial" (Marini, 1985, p. 4). La instauración de este proyecto político requirió el desmonte de las dictaduras militares que Estados Unidos contribuyó a imponer en América Latina, en tanto achicar el Estado contrariaba los intereses de las Fuerzas Armadas que habían formulado proyectos de nacionalismo exacerbado y, con ello, provocado amenazas de conflicto en la región (Marini, 1985). De esta forma, se propiciaron cambios institucionales que pudieran aplicarse sin arriesgar los sistemas de dominación vigentes, combinados con nuevos instrumentos de presión para imponer la reconversión económica; el factor determinante para impulsarlos fue, sin embargo, el surgimiento y consolidación de movimientos democráticos populares.

Con lo expuesto, se verifica la coexistencia de las perspectivas contrahegemónica y liberal desde el origen mismo de la redemocratización latinoamericana, por lo que los PP serían un caso más sobre el que ambas perspectivas pudieran tener asiento, según lo definan los actores de cada experiencia. Si la tendencia es que predomine la perspectiva liberal, ello se debe a los marcos institucionales en los que ocurre cada caso, la movilización social que se genera en torno a cada experiencia y su incidencia en los mismos marcos institucionales. Ciertamente, aunque la movilización social y los promotores de la globalización neoliberal (Santos, 2007) convergen en el escenario político-institucional democrático, los segundos han tenido mayor incidencia que los primeros. Una explicación para ello radica en las condiciones tras las dictaduras, en las que América Latina asiste al proceso globalizador: la deuda externa se convirtió en herramienta para obligar a implementar las directrices neoliberales de organismos internacionales como el Fondo Monetario Internacional y el Banco Mundial (Thwaites, 2010; Cárdenas \& Díaz, 2011); la burguesía de la región, interesada en los beneficios del modelo económico neoliberal, orientó la transición democrática, 
mientras los movimientos sociales estaban dispersos tras el periodo posdictadura. La incursión latinoamericana en la globalización fue impuesta a los países reticentes, bajo la amenaza de exclusión de la nueva y dinámica economía global (Thwaites, 2010). Además, la transición contó con el interés de la clase burguesa por la ola democratizadora impulsada por variados movimientos sociales (Marini, 1985).

Por su parte, los movimientos populares se encontraban divididos y dispersos tras la represión y dispersión impuesta en el periodo de dictaduras, en el cual los "ciudadanos se refugiaron en sus últimos reductos, aquellos de los cuales no se les podía expulsar: la fábrica, la vivienda, la escuela” (Marini, 1985, p. 10), para resistir la violación de sus derechos e impulsar la defensa abierta de los mismos. La transición hacia la democracia se vio acelerada por la endeble sustentación social de las dictaduras y los factores nacionales e internacionales contra su permanencia, generando un escenario que rebasaba la capacidad real de acción del movimiento popular. Sin embargo, aunque la movilización social latinoamericana pierde fuerza para incidir en las dinámicas globales, permanece activa en la búsqueda por incidir en ellas. La desilusión ocasionada por el sometimiento de la democracia a los dictados de los organismos internacionales se tradujo en crisis de representación, en tanto los partidos políticos se dedicaban a distribuir los cargos públicos para beneficio personal, en vez de generar los cambios institucionales exigidos por los sectores populares. Es este un factor movilizador de la fuerza social, en el que "las luchas populares abandonaron el desprestigiado ropaje partidario y se transformaron en luchas de movimientos sociales, que se deslizaron de su inicial parcialidad hacia impugnaciones e interpelaciones más globales" (Thwaites, 2010, p. 28). Es este el nicho constitutivo de las condiciones para la emergencia de los pp, fruto de fuerzas encontradas en las tendencias globalizadoras.

Es evidente, así, que los pp suceden en el marco de los cambios económicos, sociales y políticos inscritos en el metarrelato de la globalización como fenómeno mundial que impulsa estas mudanzas, las cuales fueron determinantes para propiciar los Pp: una sociedad civil que reclama espacios de participación-como por ejemplo, los PP- y un escenario político-institucional que los posibilita. La reclamación se origina en la movilización de la sociedad civil que provoca la contradicción entre el régimen político democrático y el modelo económico neoliberal; la posibilidad, a su turno, encarna las tensiones entre el marco político-institucional que promueve los PP y el modelo neoliberal que tiende a condicionarlos. En ese encuentro, la perspectiva liberal o contrahegemónica de los pp evidencia, en todos los casos, su inclinación y tendencia hacia la predominancia de la democracia sobre el neoliberalismo o, en ocasiones, a potenciarla para enfrentar los desfases neoliberales.

Entre ambas perspectivas, en ocasiones antagónicas y contradictorias, se definen los sentidos social y político del Pp, denotando que el devenir de estas experiencias no solo está determinado por las tendencias globales que suscitaron la movilización y el marco institucional necesarios para su existencia, sino que, además, puede llegar a impactarlas según las condiciones de un caso particular y sus articulaciones con otras experiencias. Esta potencialidad reside, con preeminencia, en el caso del PPLPP de Medellín, en su particular conjunción entre planeación del desarrollo y presupuesto participativo por la vía normativa, político-institucional y social. 


\section{Planeación local y presupuesto participativo de Medellín}

Los pp surgen en Colombia y Medellín tras su concepción y experimentación en otras localidades latinoamericanas y luego de la disposición normativa y social para asumir la participación como parte constitutiva del Estado colombiano. El espíritu constituyente de 1991, plasmado en la Constitución Política, definió la participación como característica y eje estructurante del país: un Estado social de derecho, organizado en forma de República unitaria, descentralizada, con autonomía de sus entidades territoriales, democrática, participativa y pluralista. Entre otras funciones, según el artículo 1, el Estado estaría llamado a facilitar la participación de todos en las decisiones que los afectan y en la vida económica, política, administrativa y cultural de la Nación. La participación también fue reconocida en el artículo 40 constitucional, garantizando a cada ciudadano la posibilidad de elegir y ser elegido; tomar parte en elecciones, plebiscitos, referendos, consultas populares y otras formas de participación democrática; constituir partidos, movimientos y agrupaciones políticas sin limitación alguna; formar parte de ellos libremente y difundir sus ideas y programas; revocar el mandato de los elegidos en los casos y en la forma que establecen la Constitución y la ley; tener iniciativa en las corporaciones públicas; interponer acciones públicas en defensa de la Constitución y la ley; y acceder al desempeño de funciones y cargos públicos. Además de derecho, participar de la vida política, cívica y comunitaria del país, según el artículo 95 constitucional, es también deber y obligación de los colombianos.

Estas disposiciones constitucionales derivaron de las mismas circunstancias relacionadas con el origen de los pP en Latinoamérica: una crisis de la institucionalidad que cuestionaba las formas representativas de la democracia y reclamaba formas directas para ejercerla.

Las iniciativas adelantadas para la institucionalización de espacios de participación en Colombia iniciaron hacia finales de la década de los 80 , cuando diversos sectores de la sociedad propiciaron la construcción de espacios alternos en la política como respuesta a la falta de confianza en los partidos tradicionales. Esta situación evidenció una cierta fractura entre la representación política y la ciudadanía. Como consecuencia, y enmarcada en un proceso de readecuación del Estado y descentralización, los mecanismos de participación directa emergieron como alternativa idónea para atender las demandas de amplias capas de la población excluidas de la toma de decisiones públicas. (Instituto de Ciencia Política Hernán Echavarría Olózaga [ICPHeO], 2012, p. 1)

Es innegable que los cuestionamientos de la sociedad civil hacia sus gobiernos, en los países de la región donde se instalaron experiencias de PP, compartían el descontento frente a las formas de representación tradicionales. Para el caso colombiano, la respuesta fue una constituyente; en ella, mediante el artículo 103, además de los principios definidos y la consagración de los derechos y deberes expuestos, se establecieron como mecanismos de participación del pueblo en ejercicio de su soberanía, el voto, el plebiscito, el referendo, la consulta popular, el cabildo abierto, la iniciativa legislativa y la revocatoria del mandato, los cuales fueron reglamentados por la Ley 134 
de 1994. Entonces, hay consonancia entre la búsqueda latinoamericana por formas de participación directa para profundizar la democracia y la declaratoria que hace Colombia para constituirse en Estado social de derecho, democrático y participativo; la hay también entre esa búsqueda y el hecho de que sus raíces estén ligadas a grupos poblacionales tradicionalmente excluidos de las esferas del poder, que demandan su incorporación en la toma de decisiones mediante mecanismos más directos.

Aun así, el espíritu democrático colombiano no escapa a su tensión con el esquema neoliberal, tal cual se presenta en el escenario latinoamericano, tensión que está manifiesta en la Constitución Política de 1991 y en el sistema legislativo, político-institucional y social del país, sus departamentos y municipios. El actual "Derecho estatal y el Constitucionalismo en particular, con sus postulados de limitación y separación de poderes, se encuentran plenamente identificados y articulados con (...) procesos neoliberales que de manera hegemónica se imponen a nivel global" (Jaramillo \& Londoño, 2012, p. 7). Al igual que en la transición a la redemocratización en otros países de América Latina, el proceso constitucional tuvo fuerte influencia de las elites de la sociedad colombiana.

En aquella ocasión la oligarquía aprovechó la coyuntura de los acuerdos de Paz con los movimientos guerrilleros M-19, Quintín Lame, PRT y EPL, para vender la idea de una "apertura democrática" a la sombra de la cual impulsaron todo el paquete neoliberal: apertura económica, privatizaciones, entrega de nuestras riquezas al gran capital, despojo y desplazamiento de la población del campo rural, y violencia paramilitar a todo granel. (Dorado, 2014, sección "No será igual a 1991")

Desde entonces, han primado los propósitos de internacionalización de la producción e inserción de las empresas y sectores económicos en la economía mundial (Montoya, 2011), en coexistencia con el ideal democrático constitucional. En este campo, el marco democrático que ofrece la Constitución de 1991, participativo por excelencia, sentó las bases para la emergencia de los pp y fue más allá, al definir que los planes de desarrollo nacional y de las entidades territoriales debían elaborarse de manera participativa y articulada entre los distintos niveles de organización territorial. Este es el escenario constitutivo para que, en Medellín, el ejercicio del pp se dinamice articulándose con los procesos de planeación del desarrollo municipal y dando lugar al PPLPP.

Las tensiones entre neoliberalismo y democracia, manifiestas desde la Constitución colombiana misma, inevitablemente permean todo su desarrollo legislativo, incluido aquel que enmarca los procesos de planeación local a nivel de comunas y de corregimientos, y los propios asociados con el pp. Aun así, puede deducirse que el caso de Medellín se corresponde más con la perspectiva liberal que con la contrahegemónica, expuestas líneas arriba, en razón a que prima la aplicación de fórmulas neoliberales en el marco de un sistema político democrático. Pero se insiste aquí en que la tendencia hacia una u otra perspectiva está determinada por las condiciones normativas, institucionales y sociales definidas en cada contexto específico, y que para el caso de Medellín, la articulación del pp con la planeación del desarrollo revela una potencialidad social y política capaz de revertir las acciones del neoliberalismo. Los mismos canales institucionales por los que se impulsa el modelo neoliberal sirven para contrarrestarlo. Lo hacen al aunar y conectar sinérgicamente 
la planeación participativa con el PP, dado que mediante la planeación se fortalece la capacidad de los actores que reciben los efectos negativos del neoliberalismo, para incidir en los escenarios donde se define la orientación económica hacia este modelo. Para entenderlo, hace falta mostrar la articulación normativa, político-institucional y social entre planeación local y presupuesto participativo que se suscita en Medellín. En tal articulación subyace el potencial social y político de esta experiencia.

La concordancia y articulación normativa es punto de partida y marco para la articulación político-institucional y social entre planeación y presupuesto participativo. Ella se genera a partir de la correspondencia entre la normatividad municipal que regula el PPLPP, con las leyes nacionales y los principios constitucionales en los que debe soportarse. Se encuentra así el Acuerdo Municipal 043 de 2007 (Alcaldía de Medellín, 2011, p. 4), mediante el cual se brindó la base jurídica para implementar el pPLPp en Medellín como estrategia de Estado, obligando su continuidad sin importar la voluntad política del gobernante de turno. El Acuerdo establece, actualiza y regula el Sistema Municipal de Planeación y, en su interior, define la planeación local y el presupuesto participativo como

el conjunto de autoridades, órganos, instrumentos y mecanismos de control, orientados al logro de los objetivos del desarrollo de las Comunas y Corregimientos, en el marco de la planeación municipal, y son parte constitutiva del Sistema Municipal de Planeación. Desde la operatividad es un proceso democrático de participación ciudadana, que permite a las y los habitantes de Medellín analizar su presente y su futuro, planear y definir propuestas de desarrollo, en el marco de los Planes de Desarrollo Local, comunal o corregimental según el caso, asignando recursos y decidiendo de forma directa cómo se debe invertir una parte de los recursos públicos en obras y servicios, de acuerdo a las necesidades prioritarias de la comunidad.

(Alcaldía de Medellín, 2011, Decreto No. 1073 de 2009, Cap. 2, art. 3)

En su capítulo vir, el Acuerdo establece tanto la forma para distribuir los recursos municipales por comunas y corregimientos, como el procedimiento para definir su inversión. Así, el artículo 39 determina que cada Plan Operativo Anual de Inversiones (POAI) deberá tener en cuenta, además de la legislación vigente y el Plan de Desarrollo Municipal (PDM), al PPLPP acordado por comunas y corregimientos. El texto del artículo 40 define que el mínimo del presupuesto de inversión del Municipio de Medellín destinado al pplpp no será inferior al 5\% del total anual aprobado, y que su distribución se haría "según criterios de Población, Índice de Desarrollo Humano, Índice de Calidad de Vida y otros que garanticen los principios de equidad social y solidaridad territorial" (Alcaldía de Medellín, 2011, p. 10).

Dos años después de su aprobación, el Acuerdo 043 de 2007 fue reglamentado mediante el Decreto 1073 de 2009, en el que se reafirma la articulación del Presupuesto Participativo con los Planes de Desarrollo Local (PDL) como insumo para las decisiones de los Consejos Comunales y Corregimentales, lo cual debería acontecer de acuerdo con el avance de cada plan, teniendo en cuenta los instrumentos de planificación que se hayan formulado en las comunas y corregimientos: planes parciales, planes sectoriales, especiales u otros. Su articulación sería responsabilidad del Departamento Administrativo de Planeación, las Juntas Administradoras 
Locales y los Equipos de Gestión de cada Plan de Desarrollo Local, con el apoyo técnico de la Secretaría Municipal de Desarrollo Social.

La complementariedad entre planeación y presupuesto participativo no se agota en lo dicho, sino que trasciende al ámbito departamental y nacional, sobre el soporte legislativo del Acuerdo 043 de 2007. La legislación que le compete está referida a la planeación del desarrollo en el país y al régimen municipal, que define la autonomía de los municipios para regularse. En el primer caso, se ubican la Ley 152 de 1994, orgánica del Plan de Desarrollo, en la que se definen el contenido estratégico y presupuestal que deben desarrollar los planes de desarrollo a escala nacional, departamental, distrital y municipal; los actores de la planeación en cada nivel; los procedimientos para la formulación de cada plan y la temporalidad para su vigencia. También se tiene la Ley 388 de 1997, que regula los mismos asuntos en materia de Plan de Ordenamiento Territorial; y la Ley 1454 de 2012 orgánica de ordenamiento territorial, que amplía los alcances de su predecesora de 1997. En materia de autonomía municipal, se encuentran las leyes 136 de 1994 de modernización, organización y funcionamiento de los municipios; la 617 de 2000, orgánica de presupuesto; y la 1551 de 2012, que ajusta la Ley 136 de 1994.

El efecto que esta normatividad tiene es vinculante respecto al Sistema Municipal de Planeación (sMP) de Medellín, en tanto define la articulación debida entre planes de desarrollo, funciones y competencias de las entidades territoriales de distinto nivel. Es esta la articulación político-institucional que se genera en el marco legislativo colombiano, que llega hasta la escala comunal y corregimental, en la que se define la planeación local y el pp incluidos en el sMp. El efecto vinculante, fundamentado en los principios de concurrencia, subsidiariedad y complementariedad entre planeación nacional, departamental y municipal, debería extenderse hasta la comuna y el corregimiento, incluyendo el contenido de los PDL en el cuerpo estratégico y presupuestal de los PDM.

Lo anterior supone una efectiva puesta en práctica de la democracia, con posibilidades reales para que la ciudadanía actúe sobre los mecanismos institucionales en los que se impone el neoliberalismo. Al realizarse la planeación del desarrollo de forma participativa en una escala tan próxima a la ciudadanía, se espera una mejor correspondencia de los PDL tanto con las necesidades de la población en cada comuna y corregimiento, como con las formas que definen para su satisfacción. Ello debería orientar las priorizaciones y ejecuciones que se realizan en el pp y, a la vez, constituirse en insumo para la formulación de los PDM, haciéndolos corresponder de mejor forma con los objetivos de desarrollo definidos por su población, e incorporando en su contenido estratégico y presupuestal las garantías para la realización de lo definido en los PDL. Esta lógica para planear es extensible al ámbito departamental y nacional, en aras de la articulación que obligan las normas sobre planeación del desarrollo en Colombia, y subvierte el orden establecido por el cual se imponen las directrices del modelo económico neoliberal. En lugar de definir desde arriba hacia abajo la planeación del desarrollo, esta se construiría desde abajo hacia arriba, en correspondencia con las iniciativas de la ciudadanía que vivencia los efectos del neoliberalismo. 
Al tiempo que la articulación normativa posibilita la articulación político-institucional, esta dinamiza la articulación social entre planeación local y presupuesto participativo. Ello ocurre en tanto el Sistema Municipal de Planeación (sMP) incorpora las "instancias y autoridades de planeación, los organismos de ejecución, administración y control y los organismos de la comunidad mediante mecanismos de información y participación y asigna competencias y responsabilidades" (Concejo de Medellín, 1996, p. 4). El smp también define como autoridades al Alcalde Municipal, el Consejo de Gobierno, el Departamento Administrativo de Planeación, la Secretaría de Hacienda y a las demás "secretarías, departamentos administrativos y oficinas especializadas en su respectivo ámbito funcional, de acuerdo con las orientaciones de las autoridades precedentes" (Concejo de Medellín, 1996, p. 4). Como instancias, incluye el Concejo Municipal de Medellín, Consejo Territorial de Planeación y las Juntas Administradoras Locales.

Especial atención merece el Consejo Territorial de Planeación, en tanto en él convergen actores sociales, gubernamentales, académicos y gremiales que participan del smp. Tienen allí representación el Departamento Administrativo de Planeación, el Concejo de Medellín, las Juntas Administradoras Locales y Juntas Administradoras Rurales, las Juntas de Acción Comunal, las organizaciones no gubernamentales (ONG) del sector social; los sectores de industria, comercio, construcción y solidario de la economía; Planeación Departamental, el Área Metropolitana, las asociaciones de profesionales, los trabajadores sindicalizados, las comunidades indígenas, las ONG ecológicas, las universidades, los colegios, los centros de investigación, las entidades u organizaciones culturales, los gremios económicos, las organizaciones de mujeres, las negritudes, el Consejo de Desarrollo Rural y el Consejo Municipal de Juventud. A los demás sectores, entidades, organizaciones y poblaciones se les permite un miembro en el Consejo Territorial de Planeación (Concejo de Medellín, 1996, 2007). Como responsables directos del pplpp en los PDM, se definió a la Secretaría de Desarrollo Social y el Departamento Administrativo de Planeación; y de acuerdo con el enfoque de corresponsabilidad incluido en los PDM, se señala como corresponsables a todas las dependencias municipales, el gobierno nacional, Agencia de Cooperación Internacional, el Área Metropolitana, la empresa privada, el sector social y las ONG. Al tratarse de un programa orientado a generar participación ciudadana, las organizaciones que se vincularon a sus iniciativas amplían el abanico de actores del PPLPP.

La importancia de reconocer a los actores definidos por el SMP desde 1996 y que ratificó en 2007, radica en su rol frente a los conceptos y procedimientos que emiten en torno a los PDM. El PPLPP, obviamente, se inscribe en las relaciones políticas que establecen estos actores al interior del sMP; el ejercicio de sus funciones y roles recae sobre el programa en el marco de la gestión, control y administración que realicen del PDM, según cada caso. De allí deriva la articulación social a la que se alude, en tanto el pplpp activa las relaciones de la ciudadanía con los demás actores del desarrollo de su municipio. Su carácter distintivo frente a otras experiencias de participación que tienen el mismo efecto, es que la planeación local define líneas y proyectos de intervención comúnmente excluidos del contenido dispuesto en los PDM y desatendidos por los actores externos a las comunas y corregimientos donde 
se realiza cada PDL. De allí que la ciudadanía tenga un punto de referencia para valorar la correspondencia entre sus propósitos y los que defienden los gobernantes elegidos para las instancias de representación; y que, en consecuencia, puede elegir de manera más acertada la opción política que mejor acoja sus iniciativas en las siguientes elecciones, controlarla y evaluarla. Si, además, se tiene en cuenta que los organismos de representación municipal se inscriben en partidos y movimientos políticos de orden nacional, al igual que la vinculación entre planes de desarrollo, la incidencia ciudadana en los escenarios de representación es extensiva al país, pasando por distritos y departamentos.

La coherencia normativa, político-institucional y social del PPLPP genera una ruta de incidencia ciudadana en las decisiones sobre su desarrollo. Esta posibilidad de incidencia, que se despliega en el marco de mecanismos de participación que activan el proyecto político democrático, tiene un efecto mayor que la mera activación de la democracia: la potencia, al punto de revertir los efectos negativos del neoliberalismo como modelo económico que define las opciones de desarrollo. Respecto de esta potencialidad, son ilustrativas tres situaciones emblemáticas que se han presentado en la puesta en práctica del programa, al tiempo que permiten derivar lecciones para construir democracia:

a. La declaratoria en desobediencia civil que realizó la comuna 1 el año 2005, argumentando que los procedimientos definidos para la priorización de recursos en el presupuesto participativo de ese año carecían de una contextualización sobre sus experiencias previas en planeación local. A partir de esa situación, se generó una parálisis en el proceso que obligó al ente gubernamental a la negociación de los procedimientos, mudando su posición inicial, que no admitía discusiones metodológicas.

b. La priorización de recursos para financiar la educación superior de jóvenes en las comunas. En principio, la oferta institucional no contemplaba esta iniciativa, pero una vez identificada la necesidad de formación superior mediante el ejercicio de planeación local, se destinaron recursos dirigidos a este propósito. Hoy, la administración municipal incluye la financiación de estudios en carreras técnicas, tecnológicas y profesionales en la oferta de iniciativas que se priorizan con recursos de Pp, y existe un programa similar que ofrece créditos a estudiantes con recursos del Fondo de las Empresas Públicas de Medellín.

c. La presencia de actores al margen de la ley que inciden en los escenarios de deliberación y decisión del presupuesto participativo, al tiempo que la institucionalidad define criterios para salvaguardar la legitimidad del proceso y las organizaciones sociales de las comunas idean sus propias estrategias no violentas para atenuar la incidencia de estos actores.

La característica común que comparten las tres situaciones es la interacción entre actores sociales y gubernamentales a través del ejercicio de planeación local y presupuesto participativo. A través de dicha interacción, los actores sociales de las comunas logran incidir tanto en los procedimientos para la toma de decisiones, como en las iniciativas sobre las que se decide (educación superior) y en las condiciones en 
las que ocurre el proceso (actores al margen de la ley). Extrapolando esta característica de la escala comunal y corregimental hacia la municipal, departamental y nacional, la articulación de planeación local con presupuestos participativos guarda una potencialidad para que la ciudadanía incida en los mecanismos de decisión, en los asuntos sobre los que se puede decidir y en las condiciones para el ejercicio participativo. La forma como se resuelven estas situaciones arroja lecciones desde la experiencia para la construcción de democracia.

En primer lugar, la experiencia enseña que los actores sociales lograrán incidencia tanto en los procedimientos para decidir como en las agendas de decisión, siempre que tengan sus propios espacios de deliberación y organización con independencia de los escenarios institucionales; ha sido en los espacios propios generados por los actores sociales donde la planeación local se ha gestado para ordenar las iniciativas de base y canalizarlas a través de planes de desarrollo local hacia los escenarios de presupuesto participativo. Aun cuando los planes de desarrollo local se ejecuten con recursos del pp, el hecho de que la ejecución esté a cargo de organizaciones sociales le imprime una dinámica propia al proceso de planeación, distinta de la que tiene lugar en los escenarios de pP coordinados por el ente gubernamental. En contraste, el tejido social se fragmenta al competir los actores por acceder a la ejecución de las iniciativas priorizadas y garantizar un sustento para sus propias organizaciones. Se han llegado a generar tensiones entre organizaciones de las comunas con aquellas que coordinan los PDL, al ponerse más atención sobre quién ejecuta el recurso que sobre los resultados y aportes que realiza al proceso de planeación.

En segundo lugar, en la práctica del PPLPP continúa difusa la mejor manera para vincular las iniciativas ciudadanas y ejecutarlas. La ley obliga a que las ejecuciones presupuestales de los municipios se realicen con base en lo consignado en sus planes de desarrollo municipal, por lo que los planes de desarrollo local tienen solo dos vías posibles: definir sus proyectos con base en el PDM o movilizarse para que sus iniciativas sean incorporadas, aun cuando no hayan sido previstas desde el comienzo. En esta decisión tiene mucho peso la disposición de la administración municipal del momento para incorporar o no la iniciativa social, en la medida en que la ley la obliga a cumplir con lo comprometido en su plan de desarrollo y restringe las posibilidades para lo que no esté allí consignado. Entonces, el que iniciativas como la financiación de educación superior con recursos de Presupuesto Participativo se incorporen a la oferta institucional, dependerá de la disposición que tenga el ente gubernamental para ajustarse a nuevas propuestas.

En tercer lugar, el PPLPP de Medellín ofrece enseñanzas para la contratación pública. Por un lado, en los ajustes que ha implicado para la ejecución de proyectos con un presupuesto inferior al límite comprendido por la ley y que serían ejecutados por organizaciones sociales; al respecto, se han aplicado diferentes estrategias, como ajustes a las normas existentes o nuevas regulaciones que posibiliten la contratación con organizaciones sociales. Por otro lado, se han aplicado distintas estrategias para la ejecución del recurso, que varían entre orientar en el sentido de que la contratación sea realizada por organizaciones de las mismas comunas, o entregar a una sola organización la ejecución de una misma iniciativa que fue priorizada en varias comunas y/o corregimientos, un "empaquetamiento" de la contratación. 
Ambas formas de ejecución de los recursos dejan en evidencia la fragmentación del tejido social frente a la necesidad de depender de fuentes de financiación públicas: las posiciones varían desde la demanda porque los recursos priorizados en cada comuna o corregimiento sean ejecutados por organizaciones de la misma jurisdicción para fortalecer sus capacidades, hasta la preferencia porque sea un actor externo quien realice la ejecución, para evitar la fragmentación de los procesos sociales por competencias frente al recurso. El mayor problema con la ejecución de los recursos es, sin embargo, la incidencia que pueden tener actores al margen de la ley en la captación del dinero público mediante la extorsión a quien ejecuta los proyectos para permitirle llevarlos a cabo; otro es el caso en que se coartan las posibilidades de deliberación y decisión de los líderes mediante amenazas. Ante esta situación, el PPLPP ha adelantado medidas institucionales, como la verificación de antecedentes penales de quienes participan en los espacios deliberativos; y también estrategias de las organizaciones sociales, como realizar las asambleas en días y horarios que de antemano saben que reducen las posibilidades de participación de los actores al margen de la ley.

Estas enseñanzas de la experiencia en Medellín denotan tanto aspectos positivos como negativos del programa. Más aún, son muestra de la tensión permanente en que se debaten experiencias de este tipo debido a la multiplicidad de intereses que convergen en ellas. Precisamente por ello, el ppLpp contiene una potencialidad para la construcción de democracia. El programa abre posibilidades de cambio que favorecen la orientación democrática del modelo económico, en la medida en que posibilita el encuentro de actores que se reconocen excluidos de los escenarios de representación; actores que dan forma a sus iniciativas mediante un ejercicio de planeación local en sus comunas y corregimientos y que procuran incidir en la inversión del presupuesto participativo, en un escenario normativo y político-institucional que no lo impide. Las posibilidades estriban en saber superar las dificultades y aprovechar los aprendizajes que dejan las enseñanzas del PpLpp. Conviene, pues, sintetizar el potencial social y político del programa para fortalecer la democracia.

\section{Potencialidad social y política del PPLPP para fortalecer la democracia}

El pplpp ha suscitado la articulación de los procesos de planeación del desarrollo local con el PP. La creación del SMP por Acuerdo 043 de 1996, su posterior ajuste y ampliación por Acuerdo 043 de 2007, su vinculación normativa y político-institucional con el Sistema Nacional de Planeación, la práctica de la planeación local y los pp, han repercutido en el proceso de planeación del desarrollo municipal. Al mismo tiempo, lo han hecho en la generación de su producto por excelencia, el PDM, aportando cambios relevantes en la concepción y metodología vinculante para gestarlo (Gutiérrez \& Sánchez, 2012).

Lo anterior expresa, entre otras cosas, mayor articulación entre PPLPP y PDM, no solo desde sus contenidos, sino mediante los aportes sociales y políticos provenientes de las vivencias en barrios, veredas, comunas y corregimientos de Medellín. Desde ellos se han gestado ejercicios de planeación local liderados por 
organizaciones sociales, cívicas, comunitarias y ONG, generando aportes al PDM que superan la articulación de sus contenidos: forman una base social actuante que se aproxima a los procesos de planeación del desarrollo, a sus enfoques y procedimientos; se capacita en metodologías para la formulación de proyectos; se reconocen las problemáticas y necesidades locales; se adelantan diagnósticos a escala veredal y barrial que orientan las intervenciones institucionales; se constituyen en referente para otros ejercicios de planeación sectorial; se proyectan iniciativas comunitarias hacia otros ejercicios de planeación, como el Plan de Ordenamiento Territorial (РОт) о intervenciones institucionales que se realizan con recurso ordinario; se provoca la articulación entre diferentes comunas y corregimientos de la ciudad mediante encuentros para debatir y compartir tanto sus PDL, como los PPLPP; se movilizan capacidades y conocimientos de las ONG; se exploran y diseñan metodologías contextualizadas a los barrios y veredas, comunas y corregimientos de Medellín; y se identifican prioridades y alternativas de solución que la ciudadanía no ve reflejadas en el contenido del PDM de turno.

En las comunas y corregimientos donde con mayor intensidad se vivencian los procesos de planeación del desarrollo y la dinámica del presupuesto participativo, la ciudadanía y sus organizaciones sociales, cívicas y comunitarias han priorizado recursos del PP para sus PDL; han implementado metodologías complementarias; diseñado sus propios mapas de barrios en atención a sus referentes territoriales; conformaron nodos para la formulación y ejecución del PDL como figura intermedia entre el barrio y la comuna; se han movilizado en torno al ejercicio de planeación, ya sea para valorarlo o criticarlo; los contenidos de los PDL han servido para orientar las discusiones en los escenarios dispuestos por el PP; han priorizado iniciativas con impacto en la ciudad, como el programa de educación superior; han formado sus líderes y lideresas en metodologías para la formulación de proyectos, en enfoques de desarrollo y nociones asociadas.

Lo que se logra hacer en las comunas y corregimientos con la planeación local, sin embargo, se encuentra limitado por actores que la ven como un ejercicio que no se concreta en su beneficio o cuyos proyectos son de tan alto costo que no podrán realizarse con recursos de PP. Aun así, la movilización que provocan repercute en una articulación de los PDL con el PDM; antes que en su contenido, en el proceso social y político que implican. Una ciudadanía que debate sobre los asuntos públicos; que comprende nociones, enfoques y metodologías de planeación del desarrollo, es lo que poco a poco se genera con el pPLPp. En ella se encuentra representado un potencial social y político para la formulación, ejecución, seguimiento y evaluación de los planes de desarrollo municipal. Si desde las comunas y corregimientos hay apuestas claras sobre los destinos de la municipalidad, los PDM consistirían en la conciliación de estas propuestas en una carta de navegación común y vinculante. La elección del gobernante atendería a quien mejor interprete dichas propuestas y cuente con las cualidades necesarias para confiarle el mandato de llevarlas a cabo. Además, conducirían a hacer de la gestión pública un escenario más participativo, transparente y democrático.

Una utopía, sin duda, ubicados en el contexto de desconfianza institucional, prácticas clientelistas e incidencia del conflicto armado en el ppLpp. Pero, precisamente 
por ello, en tanto contribuye a gestar y constituir democracia (Gutiérrez \& Sánchez, 2012), es deseable, estimulante y alentadora cuando se trata de aportar al fortalecimiento del proyecto político democrático latinoamericano, frente a las amenazas latentes, presentes y reales provenientes del modelo económico neoliberal. Es parte del sueño, de lo que está aconteciendo y aún podría acontecer en América Latina y Colombia. Desde las vivencias, aprendizajes, tensiones y realidades de la experiencia en Medellín, jotro camino para trasegar en busca de la utopía...!

\section{Referencias bibliográficas}

Aguirre, M. (2010). Transformaciones recientes del estado y la ciudadanía: una mirada a través del pp de Medellín, 2004-2008. Tesis para optar el título de Magíster en Ciencia Política, Instituto de Estudios Políticos, Universidad de Antioquia, Colombia.

Alcaldía de Medellín. (2011). ABC de Planeación Local y Presupuesto Participativo. Medellín: Autor. En http://bit.ly/1Lb45bW

Boisier, S. (2005). ¿¿Hay espacio para el desarrollo local en la globalización? Revista de la CEPAL, (86), 47-62. En http://www.cepal.org/es/publicaciones/11068-hay-espacio-desarrollolocal-la-globalizacion

Cárdenas, M. \& Díaz, F. (2011). Hegemonía en Colombia: caracterización y alternativas frente al poder global. Utopía y Praxis Latinoamericana (Revista Internacional de Filosofía Iberoamericana y Teoría Social), 16(53), 13-26. En http://www.redalyc.org/articulo. oa? $\mathrm{id}=27919220003$

Castoriadis, C. (1998). Transformaciones actuales del capitalismo y sus impactos sociales y económicos. Revista Foro, (34), 107-117.

Colombia. (1991).Constitución Política de 1991. Bogotá: Congreso de la República. En http:// www.secretariasenado.gov.co/index.php/leyes-y-antecedentes/constitucion-y-susreformas

Concejo de Medellín. (1996). Acuerdo 43 de 1996 Por el cual se crea el Sistema Municipal de Planeación y se establece el Acuerdo general para el Plan de Desarrollo de Medellín. En http://www.concejodemedellin.gov.co/webcon/concejo/concejo_gallery/1520.doc

Concejo de Medellín. (2007). Acuerdo 43 de 2007 Por el cual se crea e institucionaliza la planeación local y el PP en el marco del SMP (acuerdo 043 de 1996) y se modifican algunos de sus artículos. En www.concejodemedellin.gov.co/webcon/concejo/concejo.../1520. doc

Dorado, F. (2014). Se abrió Proceso Constituyente en Colombia. Semanario Virtual Caja de Herramientas, (393), semana del 28 de marzo al 3 de abril 2014. En http://viva.org.co/ cajavirtual/svc0393/articulo07.html

Fuentes, C. (1993). La situación mundial y la democracia: los problemas del nuevo orden mundial. El espectador-Magazin dominical, (541), septiembre.

García, N. (1995). Consumidores y ciudadanos: conflictos multiculturales de la globalización. México, D.F.: Grijalbo. 
Goldfrank, B. (2006). Los procesos de "presupuesto participativo" en América Latina: éxito, fracaso y cambio. Revista de Ciencia Politica (Santiago), 26(2), 3-28. http://dx.doi. org/10.4067/S0718-090X2006000200001

Goldin, I. \& Kenneth, R. (2005). Globalización y pobreza. Bogotá: Alfaomega.

Gómez, R. (2007). El Presupuesto Participativo entre democracia, pobreza y desarrollo. Investigación y Desarrollo, 15(1), 56-77. En http://www.redalyc.org/articulo. oa?id $=26815103$

Gutiérrez, A. \& Sánchez, L. (2009). Planeación para el desarrollo del territorio: perspectiva contemporánea. Medellín: Universidad de Antioquia.

Gutiérrez, A. \& Sánchez, L. (2012). Metodologías participativas para gestar democracia. Potencialidades del pplpp en Medellín-Colombia. En T. Villasante, M. Canales, K. Duarte, F. Palacios \& A. Opazo, Construyendo democracias y metodologías participativas desde el sur (pp. 51-74). Santiago: Lom.

Instituto de Ciencia Política Hernán Echavarría Olózaga. (2012). Ley Estatutaria de Participación Ciudadana. Observatorio Legislativo, Boletín de seguimiento (203), 1-4. En http://www.icpcolombia.org/archivos/observatorio/boletin_203

Jaramillo, J. \& Londoño, H. (2012). La globalización neoliberal y el constitucionalismo. Un análisis sobre las relaciones entre los procesos politicos y económicos de la globalización neoliberal, con el discurso y la práctica constitucional en Colombia. Tesis Magíster en Ciencias Políticas, Universidad de Antioquia, Instituto de Estudios Políticos, Medellín.

Lechner, N. (2004). ¿Cómo reconstruimos un nosotros? Revista Foro, Ciudad y gobernabilidad (Bogotá), (51), 42-58. Reproducido en Revista Humanum (PNUD), noviembre 6, 2005/Parte del Boletín No 15. En http://www.revistahumanum.org/revista/wpcontent/uploads/2012/07/01_nonbert.pdf

Marini, R. (1985). La lucha por la democracia en América Latina. Cuadernos Politicos, (44), 3-11. En http://bibliotecavirtual.clacso.org.ar/ar/libros/secret/cuadernos/marini/marini.pdf

Montecinos, E. (2009). El presupuesto participativo en América Latina. ¿Complemento o subordinación a la democracia representativa? Revista del CLAD Reforma y Democracia, (44), 145-174. En http://www.redalyc.org/articulo.oa?id=357533675005

Montecinos, E. (2011). Democracia participativa y presupuesto participativo en Chile: ¿Complemento o subordinación a las instituciones representativas locales? Revista de Ciencia Politica, 31(1), 63-89. En http://www.redalyc.org/articulo.oa?id=32419207004

Montoya, C. A. (2011). Colombia y su inserción a la economía mundial. Ecos de Economía, 15(32), 171-193. En http://publicaciones.eafit.edu.co/index.php/ecos-economia/ article/view/330

Navarro, Z. (2005). Desarrollo redistributivo y capital social: el caso del presupuesto participativo de Porto Alegre, Brasil. En I. Arriagada (Ed.), Aprender de la experiencia. El capital social en la superación de la pobreza (pp. 161-194). Santiago de Chile: Comisión Económica para América Latina y el Caribe (CEPAL). En http://repositorio. cepal.org/handle/11362/2428

Ospina, W. (2001). Colombia en el planeta. Relato de un país que perdió la confianza. Folleto impreso en Antioquia, Imprenta Departamental de Antioquia, junio de 2001. En http://fresno.org.co/150/documentos/Colombiaenelplaneta.pdf

Rodríguez, A. (1998). Desafíos para el gobierno de la ciudad en América Latina, fuerzas globales expresiones locales. Revista Foro, Ciudad y gobernabilidad (Bogotá), (34), 68-85. 
Santos, B. (2007). Dos democracias, dos legalidades: el presupuesto participativo en Porto Alegre, Brasil. En: B. Santos \& C. Rodríguez (Eds.), El derecho y la globalización desde abajo: hacia una legalidad cosmopolita (pp. 278-301). Barcelona: Anthropos/México, D.F.: Universidad Autónoma Metropolitana Cuajimalpa.

Squella, A. (1997). Una idea de globalización. Estudios Sociales (Santiago), (94), 189-196.

Thwaites, M. (2010). Después de la globalización neoliberal: ¿qué Estado en América Latina? OSAL (Observatorio Social de América Latina) (Buenos Aires: Clacso), 11(27), 19-44. En http://www.iade.org.ar/uploads/c87bbfe5-bff0-5e4e.pdf

Velásquez, C. \& González, R. (2010). La planeación participativa, el sistema de planeación y los pp en Colombia. Bogotá: Fundación Foro Nacional por Colombia.

Vélez, A., González, A., López, B., Serna, C., Zapata, C., Vélez, E., ... Sánchez, L. (2010). Planeación para el desarrollo. Una utopía realizable. Trabajo de grado no publicado, en Trabajo Social. Medellín, Universidad de Antioquia. 